\title{
TNF-alpha inhibitors: Current indications
}

\author{
Rashmi Sharma, Chaman Lal Sharma*
}

Advances in the DNA hybrid technology led to the development of various biologicals that specifically target TNF- $\alpha$. There are currently three anti- TNF- $\alpha$ drugs available- etanercept, infliximab and adalimumab. Etanercept is approved by FDA for rheumatoid arthritis (RA) in 2000 followed by its approval for ankylosing spondylitis, psoriasis and psoriatic arthritis. Infliximab and adalimumab are approved by FDA in 2002 for RA. Infliximab is also approved for ankylosing spondylitis, psoriasis, psoriatic arthritis, crohn's disease and ulcerative colitis and adalimumab for psoriatic arthritis and ankylosing spondylitis. Other conditions like bronchial asthma, diabetes mellitus, malignancies, septic shock, behcet's disease, bullous dermatitis, neutrophilic dermatitis, toxic epidermal necrolysis, systemic vasculitis, pyoderma gangrenosum, pustular dermatitis, alcoholic hepatitis, cerebral malaria, hemolytic uremic syndrome, pre-eclampsia, allograft rejection, uveitis, otitis media, snakebite, erythema nodosum, myelodysplastic syndromes, graft versus host disease, dermatomyositis and polymyositis are the potential targets for anti-TNF- $\alpha$ therapy. There are resent reports of serious infections like tuberculosis with the use of anti-TNF therapy. In developing country like India these agents should be used with strict pharmaco-vigilance and chemo-prophylaxis for tuberculosis.

Key words: Adalimumab, ankylosing spondylitis, etanercept, infliximab, psoriasis, rheumatoid arthritis, tuberculosis

Tumour Necrosis Factor (TNF)- $\alpha$, a potent cytokine is a soluble $17-\mathrm{Kd}$ protein with three identical subunits. TNF is produced by the body and is involved in normal inflammatory and immune responses. ${ }^{[1]}$ It is both autocrine and paracrine inducer of other cytokines like IL(interleukin)-1, IL-6, IL-8, platelet derived growth factor$\mathrm{B}$, ecosanoids, platelet activating factors and granulocyte monocyte colony stimulating factor. Anti TNF- $\alpha$ therapy down-regulates the monocyte capacity to produce proinflammatory cytokines and induces a shift to produce

\footnotetext{
From:

Postgraduate Department of Pharmacology and Therapeutics, Govt Medical College, Jammu, *Indian-III Hospital, UN Mission Congo (Monuc), Armed Medical Corps, India
}

\section{Correspondence:}

Dr. Rashmi Sharma, 216-A, Last Morh, Gandhi Nagar, Jammu-Tawi., J and K - 180 004, India. E-mail: rashmichams@yahoo.com more anti-inflammatory TH2 cytokine. Anti-inflammatory cytokines are IL-4, IL-10, IL-11, IL-13, IL-16, transforming growth factor $B$, soluble TNF-receptor and soluble interleukin-1 receptor. ${ }^{[2]}$

With the development of biologicals against TNF- $\alpha$, our therapeutic approach to inflammatory diseases has dramatically changed. Advances in the DNA hybrid technology led to the development of various biologicals that specifically target TNF- $\alpha$. There are currently three anti-TNF- $\alpha$ drugs available: - etanercept, infliximab and adalimumab [Table 1]. Etanercept is a recombinant fusion protein that consists of two soluble TNF- $\alpha$ p75 receptor moieties linked to the Fc portion of human IgG. ${ }^{[1]}$ It was approved by FDA for rheumatoid arthritis (RA) in 2000, followed by its approval for ankylosing spondylitis, psoriasis and psoriatic arthritis. ${ }^{[3]}$ Infliximab 
Table 1: Comparative features of anti-TNF- $\alpha$ agents ${ }^{[1-4]}$

\begin{tabular}{|c|c|c|c|}
\hline Parameters & Etanercept & Infliximab & Adalimumab \\
\hline $\begin{array}{l}\text { FDA approval } \\
\text { [diseases refractory to } \\
\text { conventional therapy] }\end{array}$ & RA, AS, Psoriasis and PsA & $\begin{array}{l}\text { RA, AS, Psoriasis, PsA, } \\
\text { Crohn's disease and ulcerative colitis }\end{array}$ & RA, AS and PsA \\
\hline Structure & $\begin{array}{l}\text { Two soluble TNF- } \alpha \text { p75 receptor } \\
\text { moieties linked to the Fc portion } \\
\text { of human IgG }\end{array}$ & $\begin{array}{l}\text { Chimeric ( } 25 \% \text { mouse and } 75 \% \text { human) } \\
\text { monoclonal antibody }\end{array}$ & A human-derived antibody \\
\hline Half life & $3-4.8$ days & 8-9.5 days & $10-13.6$ days \\
\hline Binding target & TNF- $\alpha$ and lymphotoxin $-\alpha$ & TNF- $\alpha$ & TNF- $\alpha$ \\
\hline Dose & $\begin{array}{l}25 \mathrm{mg} \mathrm{S} / \mathrm{C} \text { twice weekly or } \\
50 \mathrm{mg} \text { once weekly. }\end{array}$ & $\begin{array}{l}3 \mathrm{mg} / \mathrm{kg} \text { intravenously followed by } 2 \\
\text { and } 6 \text { weeks after } 1 \text { st infusion then } \\
\text { every } 8 \text { weeks }\end{array}$ & 20-80 mg S/C weekly \\
\hline Side effects & $\begin{array}{l}\text { Erythema, pain, swelling, itches, } \\
\text { infections etc. at the site of } \\
\text { injection, infections. }\end{array}$ & $\begin{array}{l}\text { Infections, "tuberculosis, SLE - syndrome, } \\
\text { nausea, headache, sinusitis, rash and cough }\end{array}$ & $\begin{array}{l}\text { Serious infections, neurologic } \\
\text { effects and certain malignancies } \\
\text { of the lymphoid system }\end{array}$ \\
\hline
\end{tabular}

RA - Rheumatoid arthritis, AS - Ankylosing spondylitis, PsA - Psoriatic arthritis, TNF - Tumor necrosis factor, S/C - Subcutaneously, ${ }^{*}$ Incidence of tuberculosis more than etanercept and adalimumab

[chimeric (25\%mouse and $75 \%$ human)] and adalimumab [human-derived antibody] are the monoclonal antibodies against TNF- $\alpha$ and are approved by FDA in 2002 for RA. ${ }^{[2]}$ Infliximab is also approved for ankylosing spondylitis, psoriasis, psoriatic arthritis, crohn's disease and ulcerative colitis; whereas; adalimumab is approved for psoriatic arthritis and ankylosing spondylitis. ${ }^{[3,4]}$ In the present article we are going to summarize various therapeutic indications for novel anti-TNF therapies [Table 2 and 3].

\section{Search Methodology}

Prominent rheumatology and general/internal medicine journals (MEDLINE, EMBASE, PUBMED between 2000

\begin{tabular}{|c|c|c|c|c|}
\hline Study & Disease & Active treatment & Control & Result \\
\hline ATTRACT phaselll RCT & RA & Infliximab+ MTX & MTX & Combination produced better effect. ${ }^{[2]}$ \\
\hline ASPIRE phasellI RCT & RA & Infliximab+ MTX & MTX & Combination produced better effect. ${ }^{[2]}$ \\
\hline Double blind RCT & RA & Etanercept +MTX & Either drug alone & Combination produced better effect. ${ }^{[2]}$ \\
\hline BeSt Trial (Questionnaire) & RA & MTX + Infliximab & DMRDs & MTX + Infliximab better than other DMRDs. ${ }^{[2]}$ \\
\hline Double blind RCT & AS & Etanercept & Placebo & $>$ Etanercept patients showed ASAS 50 responses. ${ }^{[9]}$ \\
\hline 3 month RCT & AS & Infliximab & Placebo & Infliximab more effective than placebo. ${ }^{[9]}$ \\
\hline Anti-TNF RCT & & Etanercept & Placebo & $\begin{array}{l}\text { At } 24 \text { weeks, etanercept more effective than } \\
\text { placebo. }\end{array}$ \\
\hline Infliximab safety database & $\begin{array}{l}\text { Pregnancy } \\
\text { with CD (131) }\end{array}$ & Infliximab exposed & Non exposed & Pregnancy outcome same. ${ }^{[17]}$ \\
\hline Double blind RCT & PsA & Infliximab & Cyclosporine & $\begin{array}{l}\text { Infliximab has efficacy and rapidity of onset of } \\
\text { therapeutic effect similar to cyclosporine }{ }^{[6,22]}\end{array}$ \\
\hline Double blind RCT & PsA & Etanercept & Placebo & $\begin{array}{l}\text { Improvement in the PASI was significantly more in } \\
\text { etanercept group then placebo. }{ }^{[23]}\end{array}$ \\
\hline Phase III, double blind trial & PsA & Infliximab & Placebo & $\begin{array}{l}\text { Infliximab through } 24 \text { weeks significantly improved } \\
\text { active PsA, including dactylitis and enthesopathy } \\
\text { and associated psoriasis. }{ }^{[24]}\end{array}$ \\
\hline Multicenter, double-blind, RCT & $\begin{array}{l}\text { PsA with failure } \\
\text { of at least } \\
1 \text { DMRD }\end{array}$ & Infliximab & Placebo & $\begin{array}{l}\text { ACR20 response at week 16, was higher in } \\
\text { infliximab group. }\end{array}$ \\
\hline Pilot study & AD & Infliximab & - & $\begin{array}{l}\text { Induction therapy with infliximab significantly } \\
\text { improved all clinical parameters. }{ }^{[2]]}\end{array}$ \\
\hline Pilot study & $\mathrm{RU}$ & Infliximab & - & $\begin{array}{l}\text { Infliximab was found to be effective both as short- } \\
\text { term (10 weeks) and long term therapy } \\
\text { ( } 50 \text { weeks) }{ }^{[30]}\end{array}$ \\
\hline ATLAS trial & AS & Adalimumab & Placebo & $\begin{array}{l}\text { Adalimumab is more effective in reducing disease } \\
\text { activity. }{ }^{[4]}\end{array}$ \\
\hline Phase II, RCT & SPS & CytoFab & $\begin{array}{l}\text { Human albumin } \\
\text { as placebo }\end{array}$ & $\begin{array}{l}\text { CytoFab promptly reduced plasma TNF- } \alpha \text { and IL-6 } \\
\text { concentrations compared with placebo. CytoFab } \\
\text { increased mean ventilator-free days and ICU-free } \\
\text { days at day } 28 .{ }^{[35]}\end{array}$ \\
\hline
\end{tabular}

RCT - Randomized control trial, RA - Rheumatoid arthritis, AS - Ankylosing spondylitis, CD - Crohn's disease, PsA - Psoriatic arthritis, AD - Atopic dermatitis, RU - Refractory uveitis, DMRD - Disease modifying drug, MTX - Methotrexate, ASAS - The multicomponent assessments in ankylosing spondylitis, PASI - Psoriasis area and severity index, ACR - American College of Rheumatology preliminary criteria for improvement, SPS - Septic shock, CytoFab - Polyclonal ovine anti-TNF fragment antigen binding (Fab) fragments 
Table 3: Clinical studies of anti-TNF- $\alpha$ agents in Indian patients

\begin{tabular}{|c|c|c|c|c|}
\hline Study & Disease & Drugs & $\begin{array}{l}\text { Number of } \\
\text { patients }\end{array}$ & Result \\
\hline Phase IIlb & RA & $\begin{array}{l}\text { Etanercept along } \\
\text { with concomitant } \\
\text { use of other drugs }\end{array}$ & 40 & ACR $20 \%$ response in $70 \%$ of patients at the end of 16 weeks. ${ }^{[2]}$ \\
\hline Clinical trial & $\begin{array}{l}\text { RA, AS, PsA and } \\
\text { juvenile RA }\end{array}$ & Infliximab & - & $\begin{array}{l}\text { ACR } 20 \text { responses were obtained in all patients of RA; } 13 \% \text { of the } \\
\text { total patients developed TB. }{ }^{[39]}\end{array}$ \\
\hline Clinical trial & AS & Infliximab & 15 & $\begin{array}{l}\text { Clinically significant improvement was found in all patients without } \\
\text { any incidence of TB after } 52 \text { weeks. }{ }^{[40]}\end{array}$ \\
\hline Clinical trial & $\begin{array}{l}\text { AS, polyarticular JIA, } \\
\text { RA, undifferentiated } \\
\text { SpA, IBD-related } \\
\text { spondyloarthritis } \\
\text { and PSA }\end{array}$ & Infliximab & 176 & $\begin{array}{l}\text { Reactivated TB developed in } 10.6 \% \mathrm{SpA} \text { patients treated with } \\
\text { standard doses ( } 5 \mathrm{mg} / \mathrm{kg} \text { ) of infliximab. }{ }^{[41]} \text { Infliximab showed } \\
\text { expected efficacy in SpA, RA and JIA }\end{array}$ \\
\hline $\begin{array}{l}\text { Open label } \\
\text { pilot study }\end{array}$ & PsA & Infliximab & 3 & $\begin{array}{l}\text { All patients attained PASI } 50 \text { by } 3.8 \text { weeks. PASI } 75 \text { was } \\
\text { attained at } 9.6 \text { weeks. Relapse occurred at a mean of } 18.6 \text { weeks } \\
\text { after the first infusion. }{ }^{[42]}\end{array}$ \\
\hline
\end{tabular}

RA - Rheumatoid arthritis, AS - Ankylosing spondylitis, PsA - Psoriatic arthritis, SpA - Spondyloarthropathy, IBD - Inflammatory bowel disease, JIA - Juvenile idiopathic arthritis, PASI - Psoriasis area and severity index, ACR - American College of Rheumatology preliminary criteria for improvement

and 2006) were searched for review papers and clinical trials published on therapeutic uses of anti-TNF therapy. All the data was collected and important evidences regarding use of anti-TNF agents were summarized in the present article.

\section{Therapeutic Indications of Anti-TNF Drugs Rheumatoid arthritis $(R A)^{[2,5]}$}

The TNF plays an important role in both pathological inflammation and joint destruction that are hallmark of RA. Anti-TNF therapy has revolutionized the approach in management of RA. In phase-III RCTs (randomized control trials) like ASPIRE and ATTRACT infliximab (3 $\mathrm{mg} / \mathrm{kg}$ or $10 \mathrm{mg} / \mathrm{kg}$ ) regimen was found to be superior to MTX (methotraxate) alone. In a double blind RCT, on 686 patients with active RA the combination of etanercept $25 \mathrm{mg}$ (subcutaneously twice a week) and oral MTX (up to $20 \mathrm{mg}$ every week) was significantly better in reducing disease activity, improving functional disability and retarding radiographic progression than MTX or etanercept alone.

In a 52-week double blind clinical trial, patients with active RA were randomized to receive etanercept $25 \mathrm{mg}$ twice weekly or MTX up to $20 \mathrm{mg}$ weekly or combination therapy. Combination therapy with etanercept and MTX improved function, quality of life and satisfaction with medication significantly better than mono-therapy. In BeSt trial (where questionnaire was filled by each patient to give the responses in relation to different anti-rheumatic drug regimens), MTX and infliximab combination found to be benefiting greatly then other DMRDs (disease modifying drugs). In a study on total of 2662 patients (infliximab $=141$; etanercept $=853$; and MTX $=1668)$, compliance with at least $80 \%$ of the expected dosages was significantly lower for etanercept and MTX patients than infliximab patients. Currently, anti-TNF therapy is recommended for patients, who fail to respond or tolerate at least 2 DMRDs including MTX.

\section{Ankylosing spondylitis (AS)}

AS affects about $0.5 \%-1.0 \%$ of the population and typically begins between the ages of 15 and 40 years. ${ }^{[5]}$ It causes painful stiffness of the spine, progressive disability and loss of independence during the prime productive years. Anti-TNF- $\alpha$ agents have been found to be very effective for the treatment of both peripheral and axial symptoms in patients with AS. ${ }^{[6,7]}$ In a double blind RCT, out of 84 patients of AS, 45 received etanercept and 39 received placebo. ${ }^{[8]}$ Significantly more etanercept patients reported ASAS (the multicomponent Assessments in AS) 50 responses at all times and ASAS 70 responses at weeks two, four and eight. Patients in the etanercept group reported lower composite and fatigue BASDAI (Bath AS Disease Activity Index) scores, lower acute phase reactant levels and improvement in spinal flexion. ${ }^{[8]}$ In a three-month clinical trial, 18 of 34 patients (53\%) treated with infliximab met the predefined response criterion, compared with three of 35 (9\%) patients receiving placebo. ${ }^{[9]}$ These improvements persisted during the open-label extension study in which all participants were given infliximab for an additional 42 weeks. ${ }^{[10]}$ In another RCT, 277 patients with AS received either etanercept or placebo. ${ }^{[11]}$ At 24 weeks, $59 \%$ of patients in the etanercept group and $28 \%$ patients of the placebo group met the ASAS-20 criteria for response. Data from Phase 
III adalimumab trial evaluating long-term efficacy and safety in AS (ATLAS trial) on 315 patients demonstrated ASAS-20 response in $58 \%$ patients receiving adalimumab at 12 weeks. ${ }^{[4]}$ At week $24,42 \%$ of adalimumab-treated patients and $16 \%$ of those receiving placebo achieved a reduction of $50 \%$ or more in disease activity. ${ }^{[4]}$ Recent trials have shown that anti-TNF therapy is more effective in AS than in RA. ${ }^{[2]}$ However, patient's benefits from long-term treatment, effects on radiological progression and long-term safety of biologic therapy are still needed to be explored.

\section{Crohn's disease and ulcerative collitis}

Stenoses and fistulas are frequent complications in patients with Crohn's disease (CD). Infliximab is effective in the treatment of patients with moderately to severely active Crohn's disease with an inadequate response to other treatment options or those with fistulizing disease. ${ }^{[13-}$

${ }^{15]}$ It is administered intravenously, generally in a schedule with initial infusions at 0,2 and 6 weeks, followed by administration once every eight weeks. ${ }^{[13,14]}$ Clinical evidence suggested that a single intravenous infusion of infliximab may be effective for induction of remission in Crohn's disease. ${ }^{[16]}$ The results of two trials suggested that CDP571, the genetically engineered human TNF monoclonal antibody, is also effective in reducing disease activity index at two weeks after an infusion. ${ }^{[16]}$ Clinical experience suggests that infliximab is also be effective when administered as corticosteroid-sparing therapy. ${ }^{[15]}$ Data from the infliximab safety database suggest that infliximab exposure during pregnancy (of the 146 identified pregnancies, 131 involved women exposed directly to infliximab and outcome data were available for 96 of these women) results in outcomes that are similar to those in the U.S. population of pregnant women and pregnant women with CD not exposed to infliximab. ${ }^{[17]}$ However, follow-up of larger numbers of pregnant women exposed to infliximab will be necessary to definitively exclude any fetal risk.

In a RCT, 20 patients of steroid-dependent ulcerative colitis received either three infusion of infliximab $(5 \mathrm{mg} / \mathrm{kg}$ ) at zero, two and six weeks and thereafter every eight weeks (group A) or methylprednisolone $(0,7-1 \mathrm{mg} / \mathrm{kg}$ ) daily for one week followed by a tapering regimen up to the minimal dose to maintain a symptom-free condition (group B). ${ }^{[18]}$ Infliximab seems to be as effective as steroids in the management of the disease. In another RCT on patients with glucocorticoid resistant ulcerative colitis, no statistically significant difference was seen between the infliximab and placebo groups. ${ }^{[19]}$ Hence, data do not support the use of infliximab in the management of moderately active glucocorticoid resistant ulcerative colitis. However, recently in a RCT patients with severe to moderately severe ulcerative colitis not responding to conventional treatment, were randomized to receive infliximab (24) or placebo (21). ${ }^{[20]}$ Seven patients in the infliximab group and 14 in the placebo group had a colectomy $(P=0.017)$ within three months after randomization. Moreover, three patients in the placebo group required operation for septic complications. The study clearly indicated the role of Infliximab $4-5 \mathrm{mg} / \mathrm{kg}$ in patients experiencing an acute severe or moderately severe attack of ulcerative colitis not responding to conventional treatment.

\section{Psoriasis and psoriatic arthritis (PsA)}

TNF- $\alpha$ inhibitors are among the new class of drugs that offer new options for psoriasis control. ${ }^{[11]}$ TNF- $\alpha$ increases in the psoriatic skin lesion and in the synovium of the inflamed joint. ${ }^{[21]} \mathrm{A}$ double blind trail by Chaudhari et al., showed a $>75 \%$ improvement in psoriasis, area and severity index score at week 10 in $82 \%$ patients receiving infliximab $5 \mathrm{mg} / \mathrm{kg}$ at weeks 0,2 and 6. ${ }^{[22]}$ Etanercept has also been shown to possess good efficacy in moderate to severe psoriasis. In a double-blind RCT (12 week study) 60 patients with PsA and psoriasis received either etanercept (25 mg twice-weekly subcutaneous injections) or placebo. ${ }^{[23]} 26$ (87\%) of etanercept-treated patients met the Psoriatic Arthritis Response Criteria, compared with seven (23\%) of placebo-controlled patients. The ACR20 (American College of Rheumatology preliminary criteria for improvement) was achieved by $22(73 \%)$ of etanercept-treated patients compared with $4(13 \%)$ of placebo-treated patients. ${ }^{[23]}$ Improvement in the psoriasis area and severity index (PASI) was significantly more in etanercept group then placebo. In a phase III, double blind trial 200 patients with active PsA unresponsive to previous treatment were randomized to infusions of infliximab $5 \mathrm{mg} / \mathrm{kg}$ or placebo at weeks $0,2,6,14$ and 22. At week $14,58 \%$ of patients receiving infliximab and $11 \%$ of those receiving placebo achieved an ACR20 response $(P<0.001) .{ }^{[24]} 64 \%$ patients receiving infliximab had at least $75 \%$ improvement in PASI compared with $2 \%$ patients receiving placebo at week $14(P<0.001) .{ }^{[24]}$ These therapeutic effects were maintained till week 24 . 
In a multicentre RCT, 104 patients with PsA (with prior failure of at least 1 DMARD therapy) received infusions of infliximab $(5 \mathrm{mg} / \mathrm{kg})$ or placebo at weeks $0,2,6$ and 14. ${ }^{[25]}$ After week 16, all patients received infliximab $5 \mathrm{mg} / \mathrm{kg}$ every eight weeks through week $50.65 \%$ of infliximabtreated patients and $10 \%$ of placebo-treated patients achieved an ACR20 response at week 16. Moreover, $46 \%$ and $29 \%$ of infliximab-treated patients achieved ACR50 and ACR70 responses respectively; no placebotreated patient achieved these end points. Hence, clinical experience so far clearly indicated the role of anti-TNF drugs in the management of psoriasis and PsA refractory to other DMRDs.

\section{Systemic vasculitis ${ }^{[26]}$}

There are encouraging uncontrolled data in humans with infliximab for anti-neutrophil cytoplasm antibody (ANCA)-associated systemic vasculitis (AASV). TNF$\alpha$ plays an important role in the pathogenesis of experimental autoimmune vasculitis and blockade of this cytokine is effective in treating established vasculitis. The therapeutic action of anti-TNF- $\alpha$ agents may be mediated by suppression of the enhanced leukocyte-endothelial interactions in this disorder. However, clinical trials are needed to establish their role in systemic vasculitis.

\section{Atopic dermatitis ${ }^{[27]}$}

Chronic use of standard therapies for atopic dermatitis (AD) is associated with variable efficacy and potential side effects. Targeted therapeutic approaches, such as the inhibition of TNF- $\alpha$, may be a novel option. In a pilot study, nine patients with moderate or severe AD received infliximab $5 \mathrm{mg} / \mathrm{kg}$ by intravenous infusion at weeks zero, two, six, 14, 22, 30 and 38 and patients were followed for 46 weeks. Induction therapy with infliximab significantly improved all clinical parameters, but this improvement was not sustained through maintenance therapy. Only two patients with severe $A D$ achieved an excellent clinical response by 46 weeks. Hence, long term RCTs are required to further establish the role of infliximab and other anti- TNF- $\alpha$ agents in atopic dermatitis refractory to standard therapies.

\section{Congestive heart failure (CHF) ${ }^{[22,28,29]}$}

Elevated TNF- $\alpha$ levels have also been observed in patients with CHF and clinical trials have been performed to examine the effects of TNF- $\alpha$ inhibitors, such as etanercept and infliximab, in such a population.
TNF- $\alpha$ exerts negative inotropic effect, recapitulates cellular and biochemical abnormalities, uncouples Badrenergic receptors from adenylate cyclase, activates metalloproteinases and provokes a hypertrophic growth response in cardiac myocytes. Hence, anti-TNF- therapy seems to hold promises in treatment of CHF. Two largescale trials of etanercept in more than 2000 patients with heart failure did not indicate any increased risk of mortality or morbidity. In a clinical trial, 150 patients with stable New York Heart Association class III or IV heart failure and left ventricular ejection fraction $<0 r=35 \%$ were randomly assigned to receive placebo $(n=49)$, infliximab $5 \mathrm{mg} / \mathrm{kg}(\mathrm{n}=50)$ or infliximab $10 \mathrm{mg} / \mathrm{kg}(\mathrm{n}=51)$ at zero, two and six weeks. It was found that neither dose of infliximab improved clinical status at 14 weeks. However, the combined risk of death from any cause or hospitalization for heart failure through 28 weeks was increased in the patients randomized to $10 \mathrm{mg} / \mathrm{kg}$ infliximab. Hence, recent evidences clearly indicated adverse effect of antiTNF therapy in patients with CCF.

\section{Refractory uveitis ${ }^{[30]}$}

In a study, 23 patients of refractory uveitis received three infliximab infusions at weeks zero, two and six. Clinical success was ascertained at week 10 and patients meeting initial criteria for success received an infusion at week 14 and every eight weeks thereafter (dose escalation permitted for breakthrough inflammation). Infliximab was found to be effective both as short-term (week 10) and long term therapy (50 weeks of therapy). However, further studies are required to establish the safety of anti-TNF therapy in refractory uveitis.

\section{Bronchial asthma and allergic conditions ${ }^{[6,31,32]}$}

It has been seen that recruitment of neutrophils and eosinophils associated with allergic condition is mediated via TNF- $\alpha$. TNF- $\alpha$ is released in allergic responses, from mast cells and macrophages via $\operatorname{lgE}$ dependent mechanisms. Anti-TNF- $\alpha$ therapy may be useful as a glucocorticoid sparing asthma therapy. Anti-TNF- $\alpha$ therapy may also be effective in the treatment of certain allergic conditions including Jarisch-Herxheimer reaction. Asthma is regarded as a Th2 type disorder, especially when associated with atopy. However, TNF $\alpha$ production is increased in severe corticosteroid-dependent asthma. Improvements in clinical and physiological measures of asthma following 12 weeks treatment with etanercept were observed in an open label uncontrolled clinical study. 
Etanercept treatment was associated with improvement in asthma symptoms, lung function and bronchial hyperresponsiveness. However, further long term RCTs are required to establish the status of anti-TNF therapy in refractory bronchial asthma and allergic conditions.

\section{Sepsis and shock}

TNF-alpha is involved in virtually all features of septic shock and multiple organ failure. Anti-TNF-alpha strategies are thus appealing and have been effective at reducing inflammation and morbidity. ${ }^{[3]}$ Evidences from various RCTs targeting TNF during sepsis, showed a small but significant benefit with anti-TNF therapeutic strategies. Strategies using monoclonal antibodies are more effective than are strategies using TNF receptor proteins. ${ }^{[34]} \mathrm{A}$ study in 2634 septic patients using a murine anti-TNF antibody showed a $3.6 \%$ significant benefit in reducing mortality. ${ }^{[34]}$ Afelimomab, the $F(a b$ ')2 fragment of a murine anti-TNF-alpha antibody has been found to be efficacious and well tolerated in 7300 patients with septic shock. ${ }^{[33,34]}$ In a Phase II, RCT, 81 septic patients with either shock or two organ dysfunctions were randomized to receive CytoFab (polyclonal ovine anti-TNF fragment antigen binding (Fab) fragments), infused as a 250units/kg loading dose, followed by nine doses of 50 units/kg every 12 hours or $5 \mathrm{mg} / \mathrm{kg}$ human albumin as placebo. ${ }^{[35]}$ CytoFab promptly reduced plasma TNF- $\alpha(P=$ $0.001)$ and IL-6 concentrations $(P=0.002)$ compared with placebo. CytoFab also significantly decreased TNF- $\alpha$ in bronchoalveolar lavage (BAL) fluid $(P<.001)$. The number of shock-free days did not differ between CytoFab and placebo. CytoFab increased mean ventilator-free days and ICU (intensive care unit)-free days at day 28. However, $41 \%$ of CytoFab-treated patients developed detectable plasma levels of human anti-sheep antibodies. ${ }^{[35]}$ However, better characterization of patients and a more multimodal approach by concomitantly targeting other mediators involved in sepsis may be helpful in enlarging the clinical benefit of anti-TNF therapy.

\section{Diabetes Mellitus ${ }^{[36]}$}

TNF- $\alpha$ related apoptosis is involved in $\beta$ cell damage in type I diabetes, resulting into insulin resistance, impaired insulin signaling and formation of atherosclerotic vascular lesions in diabetic patients. It has been documented that anti-TNF- $\alpha$ therapy may be beneficial in reducing the complications of diabetes. In a study on 4 women (52-76 years) with type 2 diabetes in danger of vision loss due to severe macular edema on hypoglycemic therapy, two infusions of infliximab $(5 \mathrm{mg} / \mathrm{kg})$ in 1-month intervals intravenously showed significant regression in macular edema. Long term RCTs are needed to establish the role of infliximab like drugs in preventing diabetic complications.

\section{Neuro-degenerative conditions ${ }^{[37]}$}

Increased TNF- $\alpha$ levels in the cerebral post-ischemic inflammatory response lead to stimulation of adhesive molecules expression, neuronal necrosis and neurodegeneration through inhibition of a vital survival signal, 1GF-I. The cytokine TNF- $\alpha$ is elevated in Alzheimer's disease, Parkinson's disease, stroke and amyotrophic lateral sclerosis. Its synthesis can be reduced via posttranscriptional mechanisms with novel analogues of the classic drug, thalidomide. Moreover, there is need to explore the role of anti-TNF agents in neuro-degenerative disorders.

\section{Other Conditions ${ }^{[6,38]}$}

Monoclonal antibodies against TNF- $\alpha$ also have a potential in the management of cachexia of cancer, skin tumors such as basal cell carcinoma, colorectal cancers and ovarian cancers. In a study on 6 patients of active adult onset Still's syndrome (AOSD), the disease improved remarkably in all patients with and after treatment with infliximab. Conditions like behcet's disease, bullous dermatitis, neutrophilic dermatitis, toxic epidermal necrolysis, systemic vasculitis, pyoderma gangrenosum, pustular dermatitis, alcoholic hepatitis, cerebral malaria, hemolytic uremic syndrome, preeclampsia, allograft rejection, otitis media, snakebite, erythema nodosum, myelodysplastic syndromes, graft versus host disease, dermatomyositis and polymyositis are other potential targets for anti-TNF- $\alpha$ therapy.

\section{Anti TNF-therapies and Indian patients}

Misra $R$, et al. in a phase Illb study involving forty patients of RA over 18 years of age (6 male: 34 females), demonstrated ACR $20 \%$ response in $25 \%, 57.5 \%$ and $70 \%$ of patients at four, eight and 16 weeks respectively after etanercept $25 \mathrm{mg}$ subcutaneous injection twice weekly for 16 weeks (along with concomitant use of prednisolone, MTX, non-steroidal anti-inflammatory drug, folic or folinic acid as prescribed earlier). ${ }^{[2]}$ The mean scores of all aspects of Short Form-36 Health Survey assessment of patient physical and mental functioning 
improved significantly from baseline. ${ }^{[2]}$ Moreover, the data from this study have shown etanercept to be efficacious and well tolerated drug in Indian patients with RA.

In another study from Kolkata during 2002-2005 on patients of RA, AS, PsA and juvenile rheumatic arthritis, ACR 20 responses were obtained in all patients of RA with infliximab $3 \mathrm{mg} / \mathrm{kg}$ dose at 0, 2 and 6 weeks; however, $13 \%$ of the total patients developed TB (tuberculosis). ${ }^{[39]}$ However, an other study on 15 patients of AS treated with infliximab (3 $\mathrm{mg} / \mathrm{kg}$ at every eight weeks for 52 weeks) showed clinically significant improvement in all patients without any incidence of TB. ${ }^{[40]}$

Data on infliximab from 176 patients (147 AS, nine polyarticular juvenile idiopathic arthritis, $12 \mathrm{RA}$, six undifferentiated spondyloarthropathy, one inflammatory bowel disease-related spondyloarthritis and one PsA) showed development of reactivated TB in 5/47 (10.6\%)
SpA patients treated with standard doses $(5 \mathrm{mg} / \mathrm{kg})$ of infliximab. ${ }^{[41]}$ This amounted to 56 times increased risk compared to baseline $(0.187 \%)$. None of the 129 patients treated with $3 \mathrm{mg} / \mathrm{kg}$ infusions at eight-weekly intervals with omission of the two-week and six-week doses of infliximab developed reactivation tuberculosis. Infliximab showed expected efficacy in SpA, RA and JIA. The lone study on etanercept showed good efficacy in 40 patients with RA. ${ }^{[41]}$

In an open label pilot study among three patients having moderate to severe plaque psoriasis, infliximab was administered in a dose of $5 \mathrm{mg} / \mathrm{kg}$ as an intravenous infusion over two hours, diluted into $500 \mathrm{ml}$ of normal saline at zero, two and six weeks. ${ }^{[42]}$ All patients attained PASI 50 by 3.8 weeks. PASI 75 was attained at 9.6 weeks. ${ }^{[42]}$ The mean improvement in PASI at week 10 stood at $77.2 \%$. Relapse occurred at a mean of 18.6 weeks after the first infusion. The first patient, who also

\section{Table 4: British society for rheumatology guidelines for prescribing TNF- $\alpha$ blockers in adults with rheumatoid arthritis $^{[5]}$}

Eligibility criteria for biologic therapy: *Fulfill 1987 criteria of American college of Rheumatology for diagnosis of RA. *Active RA (DAS28 score $>5.1$ ) at 2 points one month apart. *Failure to respond or tolerate at least 2 DMRDs (disease modifying drugs) including MTX (methotrexate). *When other DMRDs are contraindicated.

Exclusion criteria: Pregnant and lactating mothers, active infection, septic arthritis in last 12 months, sepsis of prosthetic joint within last 12 months or indefinitely if joint remains in situ, New York Heart Association (NYHA) grade 3or 4 of congestive cardiac failure (CCF) and Demyelinating disease. *Caution in patients with low immune status.

Conditions for with-drawl of biologic therapy: *Drug related toxicity. ${ }^{*}$ Failure to improve DAS28 score by 1.2 or to reduce it to a score of $<3.2$ after 3 months of therapy. However, if there is decrease in dose of DMRDs, continue drug for 6 months and assess. ${ }^{*}$ Severe intercurrent infection and pregnancy (temporary with-drawl).

Choice of anti-TNF therapy: *Patient's preference, practical issues like drug administration and delivery. *Etanercept and adalimumab can be given in patients intolerant to MTX. *Infliximab and etanercepts can be interchanged in case of failure to one of the therapy. DMRDs can be combined. Follow recommended dose.

Potential adverse effects and anti-TNF therapy:

Serious infections including tuberculosis (TB): Stop therapy, restart when infection gets resolved, not recommended in HIV+ve and HBV infection, use with caution in HCV infection.

Prior to commencing treatment screen patient according to British Thoracic Society (BTS) guidelines. Treat active TB before starting antiTNF therapy. Start prophylactic treatment in patients with evidence of potential latent disease. Monitor patients for TB during anti-TNF therapy and 6 months after discontinuation of infliximab due to prolonged elimination phase. Treat patients on anti-TNF therapy with active TB symptoms with full anti-tuberculosis chemotherapy and continue anti-TNF therapy if clinically needed. Resume anti-TNF therapy in accordance with BTS guidelines.

Surgical procedures: With held therapy 2-4 weeks before major surgery and restart after complete wound healing.

Vaccination: Live vaccines are to be given 4 weeks before commencing treatment or 6 months after last infusion of infliximab or 2-3 weeks after last dose of etanercept.

Malignancy: No evidence of associated malignancy risk. Investigate patient for any potential malignancy and stop therapy if confirmed. Caution is required in patients with previous malignancy, no contraindication if no evidence of recurrence of malignancy for 10 years.

SLE-like disease: Stop therapy and treat for SLE.

CCF/cardiovascular disease: No therapy in NYHA grade 3/4CCF. Caution in mild CCF. Monitor for CCF and stop if increases in severity.

Demyelination disease (DD) and neurological complications: Contraindicated in presence of clear history of DD, avoid if possible history of DD or family history of DD, withdraw therapy if DD occurs and refer patient to neurologist.

Haematological complications: Periodic blood counts to be done and stop therapy if pan-cytopenia occurs.

Pregnancy and lactation: Active contraception during therapy and stop treatment if pregnancy occurs. Discontinue infliximab 6 months before female becomes pregnant or male patient fathers. Avoid breast-feeding. 
had PsA, reported partial improvement in spinal stiffness and pain at two weeks and peripheral joint stiffness at six weeks. These improvements did not diminish at 22 weeks, end of the surveillance period. ${ }^{[42]}$

\section{Safety concerns with anti-TNF therapy[2,43-46]}

Reactivation of latent TB with TNF blockers is a cause of concern. More cases of TB have been reported with infliximab than with etanercept or adalimumab. This higher incidence of TB with infliximab could be because of its ability to disrupt granulomas leading to reactivation of TB and to fix the complement and lyse the cells presenting TNF- $\alpha$. Moreover, infliximab has longer half-life (210h) and can produce continuous blockade of TNF- $\alpha$ in irreversible manner in contrast to etanercept. Another point differentiating infliximab and etanercept is blockade of both TNF- $\alpha$ receptor p55 and p75 mediated events by infliximab and only p75 blockade is blocked by etanercept.

However, considering the risk of serious infections with the use of anti-TNF therapy, FDA recommended a black box for TB on the product labeling of infliximab. According to British Thoracic Society recommendations following guidelines should be observed:

1. If there is prior history of $T B$, chest $X$-ray and clinical examination positive, first treat the patient with anti- tuberculosis chemotherapy before starting anti-TNF therapy.

2. If anti-TNF therapy has to be initiated earlier, complete two months anti-tuberculosis treatment or ensure drug susceptibility of the organism before starting the antiTNF therapy.

3. If there is evidence of past history of TB or abnormal chest X-ray with complete treatment carefully monitor with chest X-ray after every three months.

4. If history of inadequate anti-TB therapy or risk of TB is more than risk of chemoprophylaxis, a full course of chemoprophylaxis should be given before starting anti-TNF- $\alpha$ therapy.

5. Tuberculin test is considered reliable only if patient is not taking immunosuppressive drugs or stopped them (one month for steroids and three months for others).

However, in developing countries like India with prevalence rate of TB of about $44 \%$, a negative Mantoux test does not rule out TB. It is recommended to consider prophylactic anti-TB therapy with Isoniazid $5 \mathrm{mg} / \mathrm{kg}$ in patients before starting anti-TNF- $\alpha$ therapy. As there is increasing trend towards multidrug resistant TB, hence prophylaxis with two or three antitubercular drugs should also be considered. SLE syndrome, demylinating diseases, neurodegenerative diseases, pancytopenia,

\section{Table 5: Current therapeutic status of anti-TNF therapy}

\section{Diseases \\ Rheumatoid arthritis (RA) \\ Ankylosing spondylitis \\ Crohn's disease \\ Ulcerative colitis \\ Psoriasis and PsA (psoriatic arthritis) \\ Systemic vasculitis, atopic dermatitis, complications of diabetes mellitus \\ Congestive heart failure (CHF)}

Sepsis and shock

Bronchial asthma and allergic conditions

Neuro-degenerative conditions, cancer, behcet's disease, bullous dermatitis, neutrophilic dermatitis, toxic epidermal necrolysis, systemic vasculitis, pyoderma gangrenosum, pustular dermatitis, alcoholic hepatitis, cerebral malaria, hemolytic uremic syndrome, preeclampsia, allograft rejection, otitis media, snakebite, erythema nodosum, myelodysplastic syndromes, graft versus host disease, dermatomyositis and polymyositis

\section{Present status of anti-TNF therapy}

Patients, who fail to respond or tolerate at least 2 DMRDs (disease modifying drugs) including methotrexate.

Patients refractory to conventional therapy

More effective than in RA.

Moderately to severely active Crohn's disease with an inadequate response to other treatment options or those with fistulizing disease.

Patients not responding to conventional and treatment; management of moderate to severe steroid-dependent ulcerative colitis.

Management of psoriasis and PsA refractory to other DMRDs.

Encouraging uncontrolled data in humans with infliximab. No anti-TNF agent approved by FDA for use in this condition

Recent evidences clearly indicated adverse effect of anti-TNF therapy in patients with CCF.

Strategies using monoclonal antibodies are more effective than are strategies using TNF receptor proteins.

No anti-TNF agent approved by FDA for use in this condition.

Encouraging uncontrolled data in humans with etanercept. No anti-TNF agent approved by FDA for use in this condition.

Potential targets for clinical studies 
cardiovascular diseases etc. are the other important adverse effects reported with anti-TNF $\alpha$ therapy. However, it has been recommended that anti-TNF drugs should not be used in pregnant and lactating mothers, active infection, septic arthritis in last 12 months, sepsis of prosthetic joint within last 12 months or indefinitely if joint remains in situ, NYHA grade 3 or 4 of CCF and demyelinating disease [Table 4].

\section{Conclusion}

Anti- TNF- $\alpha$ agents have been found very effective for the treatment of various immuno-inflammatory conditions (table-5). Currently anti-TNF drugs are approved by FDA for use in RA, PsA, psoriasis, CD, ulcerative collitis and AS. Sepsis, bronchial asthma and allergic conditions are other diseases in pipeline for approval. However, their use is limited by cost and uncertainty over long-term efficacy and safety. Etanercept, infliximab and adalimumab can be given in patients intolerant or refractory to other DMRDs. ${ }^{[5]}$ Infliximab and etanercept can be interchanged in case of failure to one of the therapy. ${ }^{[5]}$ Genetic variability in the production and effecter pathways of TNF- $\alpha$ determines the effect of anti-TNF therapy. Meta-analyses have suggested that etanercept shows modest superiority over infliximab or adalimumab. ${ }^{[47]}$ Reactivation of latent TB with TNF blockers is a cause of concern. More cases of TB have been reported with infliximab than with etanercept or adalimumab. Etanercept [Rs 20800(\$451.20)/100 $\mathrm{mg}$ ] and infliximab [Rs16500(\$357.50)/25 mg] are two biologics available in India. ${ }^{[2]}$ It is recommended to consider prophylactic anti-TB therapy before starting anti-TNF- $\alpha$ therapy, as India has $44 \%$ prevalence rate of TB. However, extensive post-marketing surveillance is necessary to re-evaluate the risk-benefit ratio of these biologic therapies. Prescriber should evaluate all the available evidences before prescribing an anti-TNF- $\alpha$ agent for various potential indications.

\section{References}

1. Mahajan A, Sharma R, Khajuria R, et al. Rheumatoid arthritis: New developments in biologic therapy. J Indian Med Assoc 2006;104:327-30.

2. Mahajan A, Sharma R, Singh JB. Biological therapy in Rheumatoid Arthritis: Current status. Indian J Rheumatol 2006;1:13-9.

3. Arya V. Food and drug administration (FDA) approval status of biologicals used in Rheumatology. Indian $\mathrm{J}$ Rheumatol 2006;1:41.

4. Waknine Y. FDA approvals: Duetact and humira. Medscape family medicine/primary care MedPulse ${ }^{\circledR}$ release. Available from: http:// www.medscape_familymed@mp.medscape.com. [Last accessed on 2006 Aug 9].

5. Ledingham J, Deighton C. Update on the British Society for Rheumatology guidelines for prescribing TNF- $\alpha$ blockers in adults with Rheumatoid Arthritis (update of previous guidelines of April 2001). Rheumatol 2005;44:157-63.

6. Singh J, Suruchi A. Anti-TNF- $\alpha$ strategy: Present status of this therapeutic paradigm. Indian J Pharmacol 2004;36:10-4.

7. Boulos P, Dougados M, Macleod SM, Hunsche E. Pharmacological treatment of ankylosing spondylitis: A systematic review. Drugs 2005;65:2111-27.

8. Calin A, Dijkmans BA, Emery P, Hakala M, Kalden J, LeirisaloRepo $\mathrm{M}$, et al. Outcomes of a multicentre randomized clinical trial of etanercept to treat ankylosing spondylitis. Ann Rheum Dis 2004;63:1594-600.

9. Braun J, Brandt J, Listing J, Zink A, Alten R, Golder W, et al. Treatment of active ankylosing spondylitis with infliximab: $A$ randomized controlled multicentre trial. Lancet 2002;359:118793.

10. Braun J, Brandt J, Listing J, Zink A, Alten R, Burmester G, et al. Long-term efficacy and safety of infliximab in the treatment of ankylosing spondylitis: An open, observational, extension study of a three-month, randomized, placebo-controlled trial. Arthritis Rheum 2003;48:2224-33.

11. Davis JC Jr, van der Heijde D, Braun J, Dougados M, Cush J, Clegg $\mathrm{DO}$, et al. Recombinant human tumor necrosis factor receptor (etanercept) for treating ankylosing spondylitis: A randomized, controlled trial. Arthritis Rheum 2003;48:3230-6.

12. Schachna $L$. The anti-TNF revolution in ankylosing spondylitis. Med J Am 2004;181:529-30.

13. Holtmann MH, Neurath MF. Anti-TNF strategies in stenosing and fistulizing Crohn's disease. Int J Colorectal Dis 2005;20:1-8.

14. Siddiqui MA, Scott LJ. Spotlight on infliximab in Crohn disease and rheumatoid arthritis. BioDrugs 2006;20:67-70.

15. Sandborn WJ. Transcending conventional therapies: The role of biologic and other novel therapies. Inflamm Bowel Dis 2001;1: S9-16.

16. Akobeng AK, Zachos M. Tumor necrosis factor-alpha antibody for induction of remission in Crohn's disease. Cochrane Database Syst Rev 2004;1:CD003574.

17. Katz JA, Antoni C, Keenan GF, Smith DE, Jacobs SJ, Lichtenstein GR. Outcome of pregnancy in women receiving infliximab for the treatment of Crohn's disease and rheumatoid arthritis. Am J Gastroenterol 2004;99:2385-92.

18. Armuzzi A, De Pascalis B, Lupascu A, Fedeli P, Leo D, Mentella $M C$, et al. Infliximab in the treatment of steroid-dependent ulcerative colitis. Eur Rev Med Pharmacol Sci 2004;8:231-3. 
19. Probert CS, Hearing SD, Schreiber S, Kühbacher T, Ghosh S, Arnott ID, et al. Infliximab in moderately severe glucocorticoid resistant ulcerative colitis: A randomized controlled trial. Gut 2003;52:998-1002.

20. Jarnerot G, Hertervig E, Friis-Liby I, Blomquist L, Karlén P, Grännö $C$, et al. Infliximab as rescue therapy in severe to moderately severe ulcerative colitis: A randomized, placebo-controlled study. Gastroenterology 2005;128:1805-11.

21. Antoni C, Manger B. Treatment of psoriatic arthritis with TNF alpha-antagonists. J Rheumatol 2003;62:235-9.

22. Behnam SM, Behnam SE, Koo JY. TNF-alpha inhibitors and congestive heart failure. Skinmed 2005;4:363-8.

23. Mease PJ, Goffe BS, Metz J, VanderStoep A, Finck B, Burge DJ. Etanercept in the treatment of psoriatic arthritis and psoriasis: $A$ randomized trial. Lancet 2000;356:385-90.

24. Antoni C, Krueger GG, de Vlam K, Birbara C, Beutler A, Guzzo C, et al. Infliximab improves signs and symptoms of psoriatic arthritis: results of the IMPACT 2 trial. Ann Rheum Dis 2005;64:1150-7.

25. Antoni CE, Kavanaugh A, Kirkham B, Tutuncu Z, Burmester GR, Schneider $U$, et al. Sustained benefits of infliximab therapy for dermatologic and articular manifestations of psoriatic arthritis: Results from the infliximab multinational psoriatic arthritis controlled trial (IMPACT). Arthritis Rheum 2005;52:1227-36.

26. Little MA, Bhangal G, Smyth CL, Nakada MT, Cook HT, Nourshargh $\mathrm{S}$, et al. Therapeutic effect of anti-TNF-alpha antibodies in an experimental model of anti-neutrophil cytoplasm antibodyassociated systemic vasculitis. J Am Soc Nephrol 2006;17:160-9.

27. Jacobi A, Antoni C, Manger B, Schuler G, Hertl M. Infliximab in the treatment of moderate to severe atopic dermatitis. J Am Acad Dermatol 2005;52:522-6.

28. Henriksen PA, Newby DE. Therapeutic inhibition of tumor necrosis factor- in patients with heart failure: Cooling an inflamed heart. Heart 2003;89:14-8.

29. Chung ES, Packer M, Lo KH, et al. Anti-TNF Therapy Against Congestive Heart Failure Investigators. Randomized, doubleblind, placebo-controlled, pilot trial of infliximab, a chimeric monoclonal antibody to tumor necrosis factor-alpha, in patients with moderate-to-severe heart failure: Results of the anti-TNF Therapy against Congestive Heart Failure (ATTACH) trial. Circulation 2003;107:3133-40.

30. Suhler EB, Smith JR, Wertheim MS, Lauer AK, Kurz DE, Pickard TD, et al. A prospective trial of infliximab therapy for refractory uveitis, preliminary safety and efficacy outcomes. Arch Ophthalmol 2005;123:903-12.

31. Vincent JL. Afelimomab. Int J Clin Pract 2000;54:190-3.

32. Howarth PH, Babu KS, Arshad HS, et al. Tumour Necrosis Factor (TNF) as a novel therapeutic target in symptomatic corticosteroiddependent asthma. Thorax. Published Online First: 15 September
2005 doi:10.1136/thx.2005.045260 (c) 2005 by BMJ Publishing Group Ltd and British Thoracic Society: [Last accessed on 2006 Dec 28].

33. Vincent JL. Afelimomab. Int J Clin Pract 2000;54:190-3.

34. Reinhart K, Karzai W. Anti-tumor necrosis factor therapy in sepsis: Update on clinical trials and lessons learned. Crit Care Med 2001;29:S121-5.

35. Rice TW, Wheeler AP, Morris PE, et al. Safety and efficacy of affinitypurified, anti-tumor necrosis factor-alpha, ovine fab for injection (CytoFab) in severe sepsis. Crit Care Med 2006;34:2484-5.

36. Sfikakis PP, Markomichelakis N, Theodossiadis GP, Grigoropoulos V, Katsilambros N, Theodossiadis PG. Regression of sightthreatening macular edema in type 2 diabetes following treatment with the anti-tumor necrosis factor monoclonal antibody Infliximab. Diabetes Care 2005;28:445-7.

37. Greig NH, Mattson MP, Perry T, Chan SL, Giordano T, Sambamurti $\mathrm{K}$, et al. New therapeutic strategies and drug candidates for neurodegenerative diseases: p53 and TNF- Inhibitors and GLP-1 Receptor agonists. Ann NY Acad Sci 2004;1035:290-315.

38. Kraetsch HG, Antoni C, Kalden JR, Manger B. Successful treatment of a small cohort of patients with adult onset of Still's disease with infliximab: First experiences. Ann Rheum Dis 2001;60:iii55-7.

39. Narayanan K, Anand KP. Two year follow up of infliximab therapy in inflammatory arthritis. J Indian Rheumatol Assoc 2005;13:7-8.

40. Singh S, Sinal VK, Chaturvedi V. Strategy to prevent tuberculosis during anti TNF therapy in juvenile ankylosing- spondylitis with low dose infliximab without loading schedule: A one year open label study of toxicity and efficacy in 15 patients. J Indian Rheumatol Assoc 2005;13:5-6.

41. Kumar A. Experience with anti-tumor necrosis factor- $\alpha$ therapy in India. APLAR J Rheumatol 2006;9:136.

42. Sridhar J, Desylva P, Singh YD. Chimeric monoclonal antibody to tumor necrosis factor alpha (infliximab) in psoriasis. Indian $\mathrm{J}$ Dermatol Venereol Leprol 2006;72:133-5.

43. Ledingham J, Wilkinson C, Deighton C. British Thoracic Society (BTS) recommendations for assessing risk and managing tuberculosis in patients due to start anti-TNF-\{alpha\} treatments. Rheumatol (Oxford) 2005;44:1205-6.

44. Attri SK. Infliximab in spondyloarthropathy. Indian J Rheumatol 2006;14:37.

45. Grover R, Kapoor S, Marwaha V. Authors' reply. Indian J Rheumatol 2006;14:37-8.

46. Tandon VR, Mahajan A, Khajuria V. TNF blockers and tuberculosis: An Indian concern. Indian J Rheumatol 2006;1:66-71.

47. Mpofu S, Fatima F, Moots RJ. Anti-TNF- $\alpha$ therapies: They are all the same (aren't they?) Rheumatol 2005;44:271-3.

Source of Support: Nil, Conflict of Interest: None declared. 